\title{
DISTRIBUSI PENYEBARAN JENIS TIKUS DAN PINJAL DI WILAYAH FOKUS PES
}

\author{
Wahyu Hilal N*, Ngadino, Koerniasari
}

Jurusan Kesehatan Lingkungan, Politeknik Kesehatan Kemenkes Surabaya

*Email korespondensi: wahyuhilal4018@gmail.com

\begin{abstract}
ABSTRAK
Pes merupakan penyakit zoonosis dari tikus yang dapat ditularkan kepada manusia melalui gigitan pinjal yang mengandung bakteri Yersinia pestis. Jenis pinjal yang dikenal sebagai vektor Pes antara lain pinjal tikus yaitu Xenopsylla cheopis, Neopsylla sondaica, Stivalius cognatus dan pinjal manusia Pulex irritans. Pada daerah fokus Pes kepadatan pinjal dan tikus perlu diwaspadai, agar tidak terjadi peningkatan kasus Pes. Tujuan penelitian ini untuk mengetahui distribusi penyebaran jenis tikus dan pinjal di daerah fokus Pes.

Penelitian ini merupakan penelitian deskriptif dengan pendekatan Observasional. Obyek penelitian yaitu tikus dan pinjal di wilayah Dusun Surorowo, Desa Kayukebek, Kecamatan Tutur, Kabupaten Pasuruan. Dimana pengumpulan data jenis tikus dan pinjal tersebut akan dipetakan dengan cara peletakan perangkap hidup (live trap) sebagai titik koordinat sampel.

Jenis spesies tikus yang tertangkap adalah R.tanezumi $74,57 \%$, Rattus tiomanicus $6,78 \%$, Rattus exulans $18,65 \%$. Didapatkan dua jenis Pinjal yang didapatkan, yaitu Xenopsylla cheopis sebanyak 68 ekor, Stivalius cognatus 16 ekor. Dengan hasil infestasi pinjal sebesar $54,23 \%$, indeks pinjal umum total sebesar 1,42 dan indeks pinjal khusus sebesar 1,15 yang terbilang tinggi. Tingginya jenis tikus pada wilayah pemukiman tersebut dikarenakan melimpahnya sumber makanan dan kondisi lingkungan yang sesuai.

Berdasarkan hasil dan kendala yang dihadapi selama pengambilan data jenis tikus dan pinjal paling tinggi berada di wilayah pemukiman. Saran yang dapat diberikan dari penelitian ini antara lain adanya penelitian mengenai hubungan kondisi rumah,terhadap penyebaran induk semang penyakit pes.
\end{abstract}

Kata kunci : Penyebaran, Tikus, Pinjal, Pes

\section{PENDAHULUAN}

Pes merupakan penyakit zoonosis dari tikus yang dapat ditularkan kepada manusia. Penyakit yang dikenal dengan nama yersiniosis/plague/sampar ini bersifat akut yang disebabkan oleh bakteri Yersinia pestis (Pasteurella Pestis). Tikus merupakan binatang pengerat (rodensia). Beberapa spesies dari kelompok binatang ini tinggal berdekatan dengan manusia dan kegiatan manusia, sehingga tikus disebut sebagai Rodensia komensal. Beberapa penyakit zoonosis di Indonesia, seperti penyakit Pes sangat berhubungan dengan jenis tikus dan ektoparasitnya. Di Indonesia terdapat empat wilayah provinsi yang menjadi daerah pengawasan penyakit Pes,yaitu di Ciwidey Kabupaten Bandung (Jawa Barat), Kecamatan Selo dan Cepogo,Kabupaten Boyolali (Jawa Tengah), di Kecamatan Tutur, Tosari, Puspo, dan Pasrepan Kabupaten Pasuruan (Jawa Timur), dan
Cangkringan Kabupaten Sleman (Yogyakarta). Pada tanggal 3 November 1986 terjadi wabah Pes di wilayah Nongkojajar tepatnya di Dusun Surorowo, Desa Kayukebek, Kecamatan Tutur, Kabupaten Pasuruan Jawa Timur terdapat 8 kasus kematian dengan gejala demam tidak jelas. Dan sejak tahun 1987 wilayah Nongkojajar Pasuruan ditetapkan sebagai daerah fokus Pes. Direktorat Jenderal Pengendalian Penyakit dan Penyehatan Lingkungan,2014).

Pada tahun 2016 terdapat 2 kasus suspect Pes tepatnya pada Dusun Surorowo,di wilayah kerja Puskesmas Nongkojajar yang masih berpotensi dapat menimbulkan wabah Pes. Sehingga pengamatan sebaran induk semang penyakit Pes harus dilakukan di daerahdaerah fokus Pes yaitu pada Dusun Surorowo, Desa Kayukebek, Kecamatan Tutur Kabupaten Pasuruan Provinsi Jawa 
Timur. Dari permasalahan tersebut diatas maka perlu dilakukan penelitian tentang Distribusi penyebaran jenis tikus dan pinjal didaerah fokus Pes. Tujuan dari penelitian ini adalah mengetahui distribusi penyebaran jenis tikus dan pinjal di daerah fokus Pes

\section{METODE PENELITIAN}

Penelitian ini merupakan penelitian deskriptif dengan pendekatan observasional. yang berbasis sistem penginderaan jarak jauh yakni Sistem Informasi Geografis (SIG) pengumpulan data jenis tikus dan pinjal akan dipetakan dengan cara peletakan perangkap hidup (Iive trap) sebagai titik koordinat. Jumlah perangkap yang dipasang adalah 200 perangkap/hari selama 5 hari sehingga jumlah keseluruhan perangkap 1000 perangkap. Pemasangan perangkap dilakukan pada 3 wilayah yaitu area pemukiman, kebun dan hutan. Untuk pemasangan perangkap di dalam rumah menggunakan 2 pasang perangkap. Sedangkan pada area kebun dan hutan perangkap dipasang secara sistem Line Transect yakni pemasangan secara garis lurus. Transek pada lokasi kebun sebanyak 2 transek dan tiap transek berjumlah 30 buah dengan jarak $10 \mathrm{~m}$ Dan pada wilayah hutan sebanyak 4 transek tiap transek berjumlah 20 buah perangkap dengan jarak $10 \mathrm{~m}$. Dalam penelitian ini umpan yang digunakan adalah kelapa goreng. Tikus yang didapatkan selanjutnya akan dibawa kelaboratorium dan dilakukan identifikasi dengan mencocokkan kunci identifikasi Tikus.

Penentuan koordinat tiap jebakan ditandai menggunakan GPS untuk mengetahui lokasi pemasangan jebakan di peta. Koordinat yang telah didapatkan kemudian dimasukkan ke dalam aplikasi Arc.GIS untuk dibuat peta lokasi pengambilan data.

\section{HASIL DAN PEMBAHASAN}

1. Keberhasilan Penangkapan Tikus (Trap Success).

Tabel 1

HASIL TRAP SUCCESS TIKUS

\begin{tabular}{cccc}
\hline $\begin{array}{c}\text { Lokasi } \\
\text { pemasangan } \\
\text { perangkap }\end{array}$ & $\begin{array}{c}\text { Jumlah perangkap } \\
\text { yang dipasang }\end{array}$ & $\begin{array}{c}\text { Jumlah tikus yang } \\
\text { tertangkap }\end{array}$ & Trap Success \\
\hline Pemukiman & 60 & 41 & $T S=\frac{41}{5 \times 60} \times 100 \%=6,83 \%$ \\
Kebun & 60 & 4 & $T S=\frac{4}{5 \times 60} \times 100 \%=0,66 \%$ \\
Hutan & 80 & 14 & $T S=\frac{14}{5 \times 80} \times 100 \%=3,5 \%$ \\
Total & 200 & 59 & $T S=\frac{59}{5 \times 200} \times 100 \%=5,9 \%$
\end{tabular}

Keterangan : TS $=$ Trap Success

Lokasi pemasangan perangkap di Dusun Surorowo tersebar di 3 wilayah yakni pada pemukiman, kebun, dan hutan. Dari hasil trapping yang telah dilakukan diketahui bahwa tikus paling banyak tertangkap pada wilayah pemukiman dengan trap success $6,83 \%$, sedangkan di kebun 0,66\% dan pada

\section{Jenis Tikus yang Tertangkap}

hutan 3,5\%. Dari ketiga wilayah tersebut hasil dari trap success masih dibawah 7\%, Kondisi ini menunjukkan bahwa adanya perbedaan kuantitatif kepadatan tikus pada area pemukiman lebih tinggi dibandingkan dengan area kebun dan hutan. 
Tabel 2

HASIL SPESIES TIKUS YANG TERTANGKAP

\begin{tabular}{|c|c|c|c|c|c|c|c|}
\hline \multirow{2}{*}{$\begin{array}{l}\text { Jenis Tikus yang } \\
\text { Tertangkap }\end{array}$} & \multicolumn{3}{|c|}{ Lokasi pemasangan perangkap } & \multirow[t]{2}{*}{ Jantan } & \multirow[t]{2}{*}{ Betina } & \multirow[t]{2}{*}{ Jmlh } & \multirow{2}{*}{$\%$} \\
\hline & Rumah & Kebun & Hutan & & & & \\
\hline Rattus tanezumi & 41 & 3 & - & 19 & 25 & 44 & $74,57 \%$ \\
\hline Rattus tiomanicus & - & - & 4 & 1 & 3 & 4 & $6,78 \%$ \\
\hline Rattus exulans & - & 1 & 10 & 9 & 2 & 11 & $18,65 \%$ \\
\hline Jumlah & 41 & 4 & 14 & 29 & 30 & 59 & $100 \%$ \\
\hline
\end{tabular}

Dari hasil survey menunjukkan spesies dan jumlah tikus yang tertangkap di Dusun Surorowo, Desa Kayukebek, Kecamatan Tutur, Kabupaten Pasuruan. Ada tiga spesies yang tertangkap, yaitu Rattus ratus diardi, Rattus tiomanicus, dan Rattus exulans. Spesies yang paling banyak tertangkap adalah R.tanezumi $74,57 \%$, Rattus tiomanicus 6,78\%, Rattus exulans $18,65 \%$.

Pada wilayah pemukiman, jenis tikus yang paling banyak tertangkap yaitu Rattus tanezumi sebanyak 41 ekor yang tertangkap di dalam rumah. Pada wilayah kebun, jenis tikus yang tertangkap yakni
Rattus tanezumi sebanyak 3 ekor, dan Rattus exulans sebanyak 1 ekor sedikitnya hasil tangkapan tikus pada wilayah perkebunan disebabkan karena tidak adanya sumber pakan pada wilayah tersebut sebab petani masih pada tahap pengobatan (pemberian insektisida). Pada wilyah hutan jenis tikus yang tertangkap yakni Rattus tiomanicus sebanyak 4 ekor, Rattus exulans sebanyak 10 ekor. Sehingga hasil tangkapan tikus paling banyak pada wilayah pemukiman penduduk yakni jenis tikus Rattus tanezumi.

\section{Indeks Pinjal Khusus}

Tabel 3

HASIL INDEKS PINJAL KHUSUS

\begin{tabular}{ccccc}
\hline $\begin{array}{c}\text { Lokasi } \\
\text { pemasangan } \\
\text { perangkap }\end{array}$ & $\begin{array}{c}\text { Jenis tikus yang } \\
\text { ditemukan }\end{array}$ & $\begin{array}{c}\text { Jumlah tikus } \\
\text { yang diperiksa }\end{array}$ & $\begin{array}{c}\text { Jumlah } \\
\text { Pinjal } \\
\text { X.Cheopis }\end{array}$ & $\begin{array}{c}\text { Indeks } \\
\text { Pinjal } \\
\text { Khusus }\end{array}$ \\
\hline $\begin{array}{c}\text { Pemukiman } \\
\text { Kebun }\end{array}$ & $\begin{array}{c}\text { Rattus tanezumi } \\
\text { Rattus tanezumi } \\
\text { Rattus exulans }\end{array}$ & 41 & 64 & IPK $=\frac{64}{41}=1,56$ \\
Rutan & $\begin{array}{c}\text { Rattus exulans } \\
\text { Rattus tiomanicus }\end{array}$ & 14 & $-\frac{0}{4}=0$ & IPK $=\frac{4}{14}=0,28$ \\
Total & 59 & 4 & 68 & IPK
\end{tabular}

Keterangan : IPK = Indeks Pinjal Khusus

Tikus yang berhasil ditemukan menunjukkan presentase infestasi pinjal sebesar 50,79\% dengan jumlah tikus yang terinfestasi pinjal sebanyak 32 ekor dari 63 tikus yang tertangkap. Hal ini menunjukkan sebagian besar tikus yang tertangkap ditemukan pinjal pada tubuhnya dengan 2 spesies pinjal tikus yakni Xenopsylla cheopis, dan Stivalius cognatus. Dari banyaknya tikus yang terinfestasi pinjal di suatu wilayah menunjukkan perlu ditingkatkan kewaspadaan akan kemungkinanya terjadinya penularan pes.
Berdasarkan hasil pada Tabel 3 diketahui bahwa indeks pinjal khusus di lokasi pemukiman sebesar 1,56 dengan tikus jenis Rattus tanezumi, di kebun sebesar 0 tidak ditemukan pinjal jenis $X$.Cheopis dari jenis tikus Rattus tanezumi, dan Rattus exulans, sedangkan pada lokasi hutan sebesar 0,28 dengan jenis tikus Rattus exulans, dan Rattus tiomanicus. Indeks pinjal khusus total sebesar 1,15. Menurut WHO (1988) dalam pedoman pemberantasan pes di Indonesia tahun 1999, suatu wilayah dikatakan waspada terhadap 
penularan pes jika indeks khusus pinjal (X.cheopis) $>1$.

4. Indeks Pinjal Umum

Tabel 4

HASIL INDEKS PINJAL UMUM

\begin{tabular}{ccccc}
\hline $\begin{array}{c}\text { Lokasi } \\
\text { pemasangan } \\
\text { perangkap }\end{array}$ & $\begin{array}{c}\text { Tikus yang } \\
\text { diperiksa }\end{array}$ & \multicolumn{2}{c}{ Jenis pinjal yang ditemukan } & Indeks \\
\cline { 3 - 4 } & & X.cheopis & S.cognatus. & $\begin{array}{c}\text { Pinjal } \\
\text { Umum }\end{array}$ \\
\hline Pemukiman & 41 & 64 & 15 & IPU $==\frac{79}{41}=1,92$ \\
Kebun & 4 & - & - & IPU $==\frac{0}{4}=0$ \\
Hutan & 14 & 4 & 1 & IPU $==\frac{5}{14}=0,35$ \\
Total & 59 & 68 & 16 & IPU $_{\text {total }}=\frac{84}{59}=1,42$ \\
\hline
\end{tabular}

Keterangan : IPU = Indeks Pinjal Umum

Ektoparasit yang diperoleh adalah dua spesies pinjal yaitu Xenopsylla cheopis dan Stivalius cognatus. Tikus $R$. tanezumi merupakan jenis tikus yang paling banyak terinfeksi oleh pinjal baik Xenopsylla cheopis maupun Stivalius cognatus (Tabel V.3). Dengan persentase infestasi pinjal sebesar 54,23 \% dengan jumlah tikus yang terinfestasi pinjal sebanyak 32 ekor dari 59 tikus yang tertangkap Maka Dusun Surorowo termasuk kedalam kategori waspada terhadap penularan penyakit pes berdasarkan pada hasil infestasi pinjal sebesar $54,23 \%$, indeks pinjal umum tota1 sebesar 1,42 dan indeks pinjal khusus sebesar 1,15 terbilang tinggi.

\section{Peta Penyebaran Jenis Tikus}

Berdasarkan hasil identifikasi distribusi penyebaran jenis tikus terhadap 63 tikus di Dususn Surorowo,Desa Kayukebek, Kec.Tutur, Kab.Pasuruan yang ditangkap dengan menggunakan single life trap didapatkan 3 jenis mamalia kecil yang tergolong kedalam genus (Rattus), famili (Muridae) dan ordo (Rodentia) yang penyebarannya tersebar pada wilayah pemukiman penduduk cukup luas dan area hutan yang cukup dekat lokasi pemukiman. Jenis-jenis yang didapatkan, yaitu Rattus tanezumi, Rattus tiomanicus, Rattus exulans.

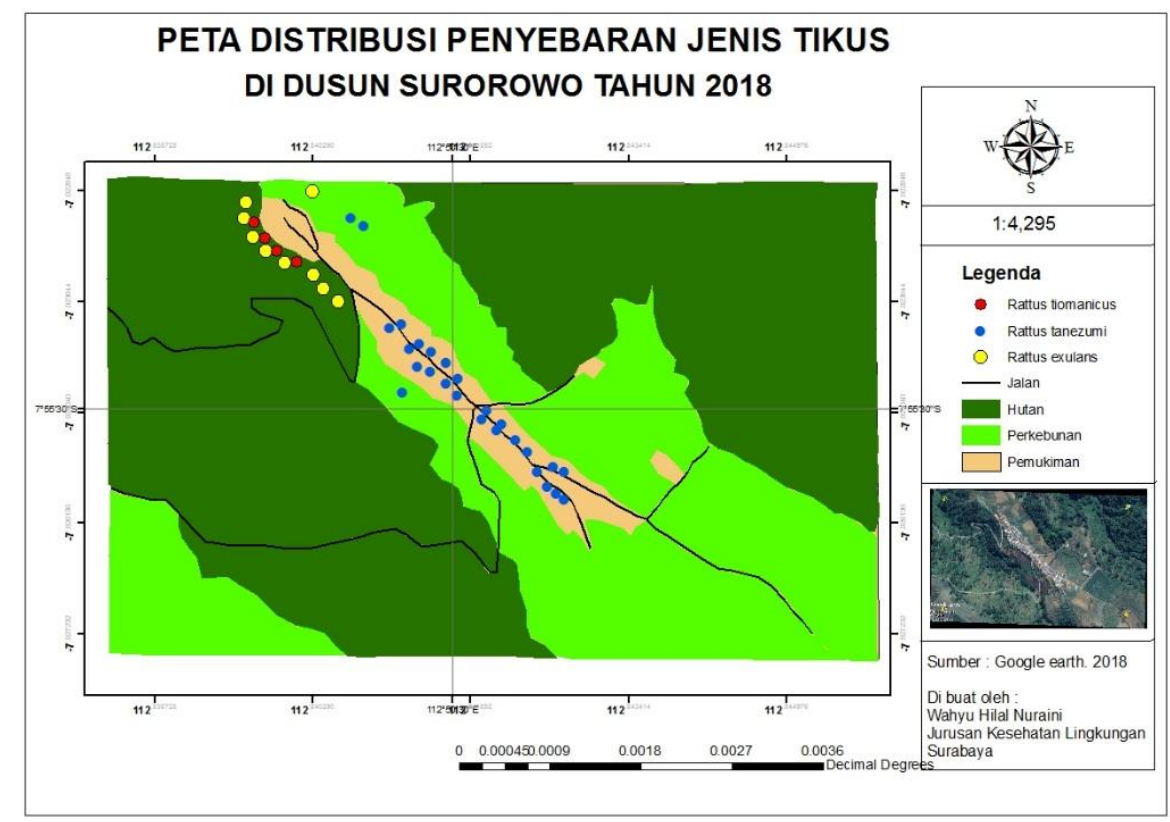

Gambar 1 DISTRIBUSI PENYEBARAN JENIS TIKUS 
6. Peta Penyebaran Jenis Pinjal

Berdasarkan hasil identifikasi distribusi penyebaran jenis pinjal terhadap 59 tikus didapatkan pinjal sebanyak 84 ekor di Dusun Surorowo, Desa Kayukebek, Kecamatan Tutur, Kabupaten Pasuruan didapatkan 2 jenis pinjal yang tergolong kedalam dua genus (Xenopsylla dan Stivalius), satu family (Pulicidae) dan satu ordo (Siphonaptera) yang penyebarannya tersebar pada wilayah pemukiman penduduk cukup tinggi dan area hutan yang dekat lokasi pemukiman. Jenis-jenis yang didapatkan, yaitu Xenopsylla cheopis sebanyak 68 ekor, Stivalius cognatus 16 ekor.

Penyebaran jenis pinjal tikus pada wilayah pemukiman memang cukup tinggi dengan indeks pinjal umum total sebesar 1,33 dengan jumlah pinjal jenis Xenopsylla cheopis sebanyak 68 $(80.95 \%)$ maupun Stivalius cognatus sebanyak $16(19,05 \%)$ dari jenis tikus Rattus tanezumi, dan Rattus exulans.

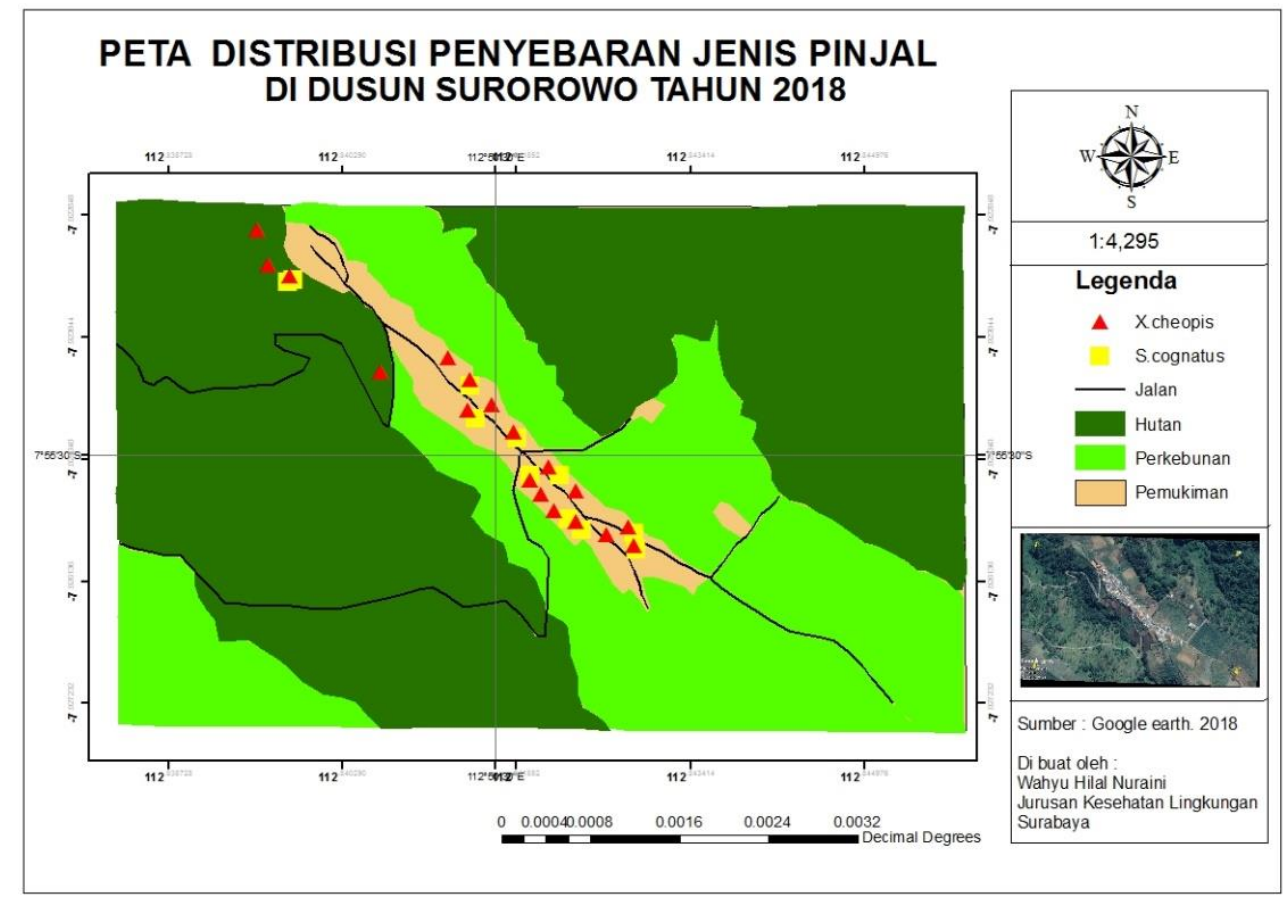

Gambar 2 DISTRIBUSI PENYEBARAN JENIS PINJAL

\section{KESIMPULAN}

Hasil pemetaan menunjukkan bahwa jenis tikus yang ditemukan ke dalam satu genus (Rattus), satu famili (Muridae) dan satu ordo (Rodentia) dan jenis pinjal yang ditemukan 2 jenis pinjal yang tergolong kedalam dua genus (Xenopsylla dan Stivalius), satu famili (Pulicidae) dan satu ordo (Siphonaptera) yang penyebarannya tersebar pada wilayah pemukiman penduduk cukup luas dan area hutan yang cukup dekat lokasi pemukiman. Jenis-jenis yang didapatkan, yaitu : Rattus tanezumi, R.tiomanicus, R.exulan. Jenis pinjal yang didapatkan, yaitu : Xenopsylla cheopis dan Stivalius cognatus dengan reservoir paling banyak pada jenis tikus Rattus tanezumi.

\section{SARAN}

Saran yang dapat diberikan kepada masyarakat agar waspada terhadap upaya penularan pes dengan meningkatkan upaya pengendalian mandiri seperti trapping yang dilakukan secara mandiri sehingga tempat-tempat perkembangbiakan tikus dapat ditekan keberadaannya. Bagi Dinas Kesehatan, informasi penyebaran jenis tikus dan pinjal dapat digunakan sebagai bahan masukan ataupun pertimbangan untuk merumuskan kebijakan dalam menangani penyakit pes serta untuk meningkatkan program pencegahan dan 
pengendalian penyakit pes dalam upaya menurunkan populasi tikus dan pinjal.

\section{DAFTAR PUSTAKA}

Balai Litbang Pengendalian Penyakit Bersumber Binatang, 2011. Buku Saku Megenal Penyakit Pes / Plague. Banjarnegara:Kementrian Kesehatan Republik Indonesia.

Direktorat Jenderal Pengendalian Penyakit dan Penyehatan Lingkungan, 2014. Petunjuk Pengendalian Pes. Jakarta, Kemetrian Kesehatan Republik Indonesia

Raharjo, Jarohman dan Tri Ramadhani. 2012. Studi Kepadatan Tikus dan Ektoparasit (Fleas) pada Daerah Fokus dan Bekas Pes. Prosiding Seminar Nasional Kesehatan
Semiadi G., Nugoho R. T. P., 2005, Panduam Pengamatan Reproduksi pada Mamalia Liar, LIPI, Bogo

Suyanto, Agustinus, 2006, Rodent Di Jawa, LIPI Seri Panduan Lapangan, Psusat Penelitian Biologi, Lembaga Ilmu Pengetahuan Indonesia, Bogor.

Sucipto, C.D, 2011. Vektor Penyakit Tropis.Yogyakarta,GosyenPublishi ng:178-179.

Yuliadi, Muhidin, Siska Indriyani. 2016. Tikus Jawa Teknik Survei Di Bidang Kesehatan. Jakarta: Lembaga Penerbit Badan Penelitian dan Pengembangan Kesehatan Kementerian Kesehatan RI. 